\title{
Shaping Blue Growth: Social Sciences at the Nexus Between Marine Renewables and Energy Policy
}

\author{
Sandy Kerr, Laura Watts, Ruth Brennan, Rbys Howell, \\ Marcello Graziano, Anne Marie O'Hagan, Dan van der \\ Horst, Stephanie Weir, Glen Wright, and Brian Wynne
}

\begin{abstract}
The development of the Marine Renewable Energy (MRE) industry is part of the EC Blue Growth Strategy. It brings together a range of relationships across people, sea, and energy, from developers to local communities and policymakers. This calls for diverse approaches, moving beyond an oppositional mindset to one that can establish an inclusive community around MRE development. Ownership of the marine environment is a legal issue, but MRE devices operate within a cultural and emotional
\end{abstract}

\footnotetext{
S. Kerr $(\bowtie) \bullet$ S. Weir

International Centre of Island Technology, Heriot-Watt University, Edinburgh, UK

e-mail: s.kerr@hw.ac.uk; Sw34@hw.ac.uk

L. Watts $(\bowtie)$

Institute of Geography and the Lived Environment, Edinburgh University, Edinburgh, UK
}

Technologies in Practice, IT University of Copenhagen, Copenhagen, Denmark e-mail: 1.watts@ed.ac.uk

(C) The Author(s) 2018

C. Foulds, R. Robison (eds.), Advancing Energy Policy, https://doi.org/10.1007/978-3-319-99097-2_3 
sense of place. Early, sustained community engagement and advocacy is crucial to developing an industry whose impacts are likely to be felt before its social benefits materialise. Crucially, local communities could be supported by Social Sciences and Humanities (SSH) research in creating new mythologies and imaginaries through which MRE technologies become an integral part of their culture, as well as part of their biophysical environment. A complex physical, political, and legal environment provides the context for these new marine energy technologies, and its development provides opportunities for SSH research to address issues around the sea and to integrate into the design of new marine energy seascapes.

Keywords Marine energy $\bullet$ Engagement $\bullet$ Mythologies $\bullet$ Disparities $\bullet$ Communities • Tidal $\bullet$ Wave

R. Brennan

Trinity Centre for Environmental Humanities, School of Histories and Humanities, Trinity College, Dublin, Ireland

e-mail: Ruth.Brennan@tcd.ie

R. Howell

School of Social and Political Science, Edinburgh University, Edinburgh, UK e-mail: rhys.howell@ed.ac.uk

M. Graziano

Department of Geography and Environmental Studies, Central Michigan University, Mount Pleasant, MI, USA

e-mail: grazilm@cmich.edu

A. M. O'Hagan

MaREI Centre, Environmental Research Institute, University College Cork, Cork, Ireland e-mail: a.ohagan@ucc.ie

D. van der Horst

Institute of Geography and the Lived Environment, Edinburgh University, Edinburgh, UK

e-mail: Dan.vanderHorst@ed.ac.uk

G. Wright

Institute for Sustainable Development and International Relations, Paris, France e-mail: glen.wright@iddri.org

B. Wynne

Department of Sociology, Lancaster University, Lancaster, UK

e-mail: b.wynne@lancaster.ac.uk 


\subsection{INTRODUCTION}

Marine Renewable Energy, generating electricity from the movement of either the waves or tides, is a developing industry, with offshore commercial deployment of small arrays of devices now underway. For example, the MeyGen project in the north of Scotland has $6 \mathrm{MW}$ on-grid capacity in the water, generated by four tidal energy devices, and is planned to expand to $398 \mathrm{MW}$. Around the world, there are around 40 open-sea test facilities for MRE. For the industry in the North Atlantic and elsewhere to grow, we must understand its relationship with our coastal communities. While academic research on land-based renewables abounds, the turn towards the sea is still in its infancy.

EU energy policy has been highly successful in making 'first generation' renewable technologies (e.g. solar and wind) commercial. Maritime policy is now focused on the innovation and Blue Growth of 'next generation' ocean energy. With an enabling regulatory framework, this technology could supply 10\% of the EU's power demand by 2050 (Ocean Energy Europe (OEE) 2016). As a recent use of marine space, MRE raises not only scientific and technical challenges but also social challenges in places with deep physical, psychological, and spiritual connections to the sea. What are the effects of marine renewables on seascapes and the marine environment (Haggett 2008; Ladenburg 2008)?

Social Sciences and Humanities (SSH) research can improve the design/ assessment of, and interaction with, complex sociotechnical issues, such as the energy transition, yet it remains underutilised in energy policy, especially in a marine context. To address this, members of the International Network for Social Studies of Marine Energy (ISSMER), an academic network formed to engage with this issue, held a two-day workshop in February 2018 in Edinburgh. Four representatives from MRE were invited, and together we discussed the response of the nascent MRE industry to social issues and considered the role and outlook for SSH research. Our four guest experts, representing MRE developers, government, and local community, engaged in lively and enlightening discussions with ISSMER researchers. This paper summarises that discussion.

Each guest posed a 'big question' to start the conversation, which was then directed towards key research domains. From these exchanges, five important themes emerged: rights and ownership, community mythologies, disparities, design, and the need for an ecology of approaches. These themes, presented below, reflect a broad range of important $\mathrm{SSH}$ factors relevant 
to MRE development. We include quotes from stakeholders; however, in accordance with the request of some stakeholders, their identity is kept confidential. In our conclusion, we reflect on the need for sustained engagement and the potential for advocacy by SSH.

\subsection{Rights ANd OWNERShip}

"We need to create a sense, or reality, of ownership"-guest expert on the imperative for community control over resources.

MRE often requires exclusive use of marine space, since devices are anchored to the seabed and are, for practical purposes, permanent. Rights and ownership issues take diverse forms in the marine environment, from legal ownership of the devices themselves to the de facto ownership of the sea and seabed (backed by a lease or consent from the State). Certain common rights in the sea, such as fishing and navigation, may also have a legal underpinning. Many coastal communities place value on their traditional rights of access to maritime resources, which may not be codified in law, for example, First Nation rights (Wright et al. 2016). Physical and emotional proximity to the sea can generate a powerful sense of ownership. In many coastal societies, the sea is inextricably linked to community and identity. Some Pacific island communities see the environment, people, and custom as bound in a single concept, 'vanua', with no clear distinction between land and sea (Batibasqa et al. 1999). Communities may feel their common rights and well-established relationship with the sea are disavowed when a new industry disrupts their marine experience, by introducing visual or other changes, or by blocking access to their coastline. The MRE industry brings the tensions between these differing notions of ownership and relationality to the fore.

Whereas terrestrial planning systems have evolved around existing patterns of privately owned land, the situation at sea is more complex (Jay 2010). Landowners can generally use their land as they wish, with the government impinging on these private rights only where necessary to preserve legal order and protect the public interest (Johnson et al. 2013). At sea, States claim sovereign jurisdiction over their coastal waters, and private ownership of marine spaces remains rare. In many places, the sea is considered a commons, public good, or free for all to use, and legal regimes generally reflect this (Smith et al. 2012). The perception of the marine environment as being a 'public good' is even stronger in cultures 
or communities with close connections to the sea, precisely the communities that are seeing new industries develop on their shore. As the Blue Economy grows and seeks new capital opportunities, what was once considered a commons is being enclosed, as leases for maritime activity, such as MRE, are granted.

MRE developers occupy a peculiar position in a local community. They have quasi-ownership of a sea area (through their lease) and yet the seas are owned by the State on behalf of its citizens. MRE is generally located close to shore, with significant onshore building works and associated social and environmental impact. Resistance by a local community to MRE could close both business case and national resource. There is little margin for error in the development of MRE, especially tide energy, for which there are only a few viable locations.

Developers must acquire a lease to access the tide or wave resource, and also work with communities to ensure that their energy generation does not impinge upon local 'moral' ownership. Failure by a developer to take into account changing patterns of ownership, or initial suspicion by a local community towards MRE, can quickly lead to protest and conflict (De Groot et al. 2018). While marine planning policies are evolving, the focus has tended to be on established activities or the tension between development and conservation (Jones et al. 2013).

The question of ownership has implications beyond access to sea space. In some regions, direct financial payments to nearby communities have emerged as a way of easing tensions (e.g. wind power in Scotland). Alternatively, the State has granted rights over resources directly to communities, providing income in the form of rent or profits (Kerr et al. 2017). Communities must then discharge the decision-making responsibilities that come with such rights, leading to additional benefits in the form of increased social cohesion and empowerment (Rennie and Billing 2015).

A community may take figurative 'ownership' of a particular MRE device or project. Indeed, the origin stories of many renewable energy industries are strongly rooted in particular places and instil pride in their communities (Devine-Wright 2009). This personal connection might create a willingness to compromise in disputes over marine space.

While developers need only meet statutory requirements to acquire legal rights to occupy the sea space and exploit marine energy resources, they must also balance this with the rights and prerogatives of other sea users. There is little precedent, here, as few commercial developments 
have completed the planning process. It would be useful to develop some guidance. For example, maintaining a 'Social Licence to Operate' (SLO) could require community engagement and recognition of important values beyond the minimum regulatory requirements, and stretch inland, as infrastructural needs of the electricity grid emerge.

In short, there is growing public concern and research around ownership of maritime resources (Kerr et al. 2015). 'Blue Growth' industries like MRE are transferring rights of access and ownership from commons to private ownership. Social Sciences have an important role to play in understanding the tension between the legal rights of individual developers and strongly held 'sense' of ownership experienced by many coastal communities.

\subsection{Community Mythologies}

"It's getting to the stage where it becomes a part of them"-guest expert reflection on how marine renewable development can fit with how local communities interpret and imagine the world.

Mythologies and imaginaries are ways of understanding the world that help us to make sense of complex social issues (Anderson 1999; Levy and Spicer 2013). They are "imaginative patterns, networks of powerful symbols that suggest particular ways of interpreting the world" (Midgley 2004 , p. 1). Existing mythologies around the sea influence how MRE technologies are received by communities. For example, the story of a small group of blacksmiths and teachers in West Jutland who became the Danish wind energy industry, backed by the Danish Government, provides a powerful 'from the people' origin myth for Denmark's wind industry (Graziano et al. 2017). How can communities be supported in creating new imaginaries through which MRE technologies become an integral part of their cultural as well as biophysical environments?

Since MRE is still in development, its mythologies have not yet been defined. This presents an opportunity for coastal communities to shape MRE mythologies appropriate to their particular socio-cultural context. In contrast, mythologies embedded in unsustainable investor hype around the industry (necessary for attracting financial support) should not be misinterpreted by communities as a likely source of local jobs or income. SSH researchers can manage MRE mythologies-in-the-making: for example, the future freezing of renewable energy subsidies in the UK could affect the way communities and the public view these technologies. 
Communities need to be supported by consistent, locally rooted, and enduring mythologies around new energy technologies, particularly where they may be perceived as creating benefits for some (such as device developers) and obstacles for others (such as fishers displaced from fishing grounds). Establishing a culture and practice of sharing stories about these new technologies between marine communities (regionally, nationally, and across Europe) could be fundamental to the creation of new futures that speak to people at a grassroots level. Pioneering communities who have hands-on experience of new energy technologies could convey their nuanced understanding to those communities following in their footsteps. Their voices are more likely to be seen as untainted by the profit motive of developers. Communities can also prepare their mythologies for what might happen in their sea, as the industry matures in the years to come. Thus, a mythology could embrace the potential for co-existence with developers, and community ownership of devices in the future.

We propose creating a new cohort of SSH-informed marine 'architects' (local community 'designers' as distinct from statutory planners), who could ensure that socio-cultural issues, including mythologies, are embedded in MRE practices and policy from the outset. This could help communities, policymakers, and developers to recognise and accommodate an ecology of different relationships in bringing this new industry to maturity.

\subsection{DisParities}

"Tidal regions must be developed intelligently to make best use of the resource"-guest expert on the small number of locations with tidal energy resources and how we must develop each one with care.

MRE operates across a complex physical, political, and legal environment, and there are a number of disparities that affect project development. These form opportunities for SSH research to inform and guide the intersection between industry, government, community, and environment.

Coherent marine management and planning is a recent undertaking, as governments grapple with Blue Growth. Marine governance has been driven by the dual forces of economic development and conservation. MRE devices are being developed by for-profit firms, potentially both contributing to, and clashing with, conservation objectives. 
An additional disparity arises between the treatment of fossil fuels and renewables. While it is widely acknowledged that rapid de-carbonisation of our energy systems is necessary, path dependencies and established subsidies for fossil energy often mean that renewables are at a disadvantage. MRE developers feel hamstrung by burdensome environmental monitoring requirements, implemented due to uncertainty regarding their environmental interaction. By contrast, oil and gas projects benefit from decades of often state-supported offshore fossil fuel extraction. Even offshore wind has fewer environmental designations and existing maritime activities to contend with, since it is situated further out to sea.

Whereas communities have been developing onshore wind projects for decades, there is less potential for the development of community-owned MRE due to its high risk. Marine energy is likely to remain centralgovernment and/or private investment owned for the near future.

The highly localised character of MRE makes it difficult to draw lessons from one project, community, or country, which can benefit others. For example, the positive community narrative regarding marine energy in Orkney, Scotland, which has seen considerable investment in both projects and community engagement, is different from projects elsewhere (see comparison between Orkney and Denmark in Watts and Winthereik 2018). There are disparities between communities and environmental contexts where projects are proposed.

MRE technologies also face different challenges. Tidal stream technologies (generating electricity from tidal flow) are the most advanced, but the worldwide availability of exploitable resources is limited. Wave energy technologies are yet to coalesce around a particular design, but there are more potential sites of resource. MRE technologies suffer from disparities in their spatiality and timing, and expectations that hold for tide energy might not hold for wave energy.

Compounding these disparities is the resource expectation. Terrestrial sources of renewable energy, such as wind, are relatively abundant, allowing developers a certain level of flexibility in selecting appropriate sites. By contrast, the number of potential sites for marine energy is much more limited. This means that developers must develop projects in those specific places and ensure that the community supports their projects. Community engagement, and a well-established socio-cultural relationship with marine energy, is therefore vital. As such, SSH concerns are central to negotiating across the many disparities in MRE development. 


\subsection{DESIGN}

"We need new stories. It doesn't matter if they are 'right' or not. What matters is the creation of fresh stories and ideas"-guest expert on community consultation as part of the design process for shaping future energy infrastructure.

The design process for MRE is, at present, focused on environmental and technical concerns, but social and cultural issues also emerge at each step of the design, development, and deployment process. MRE devices require environmental, technical, and social issues all to be resolved, and these are both related together and relational by nature. How might we design MRE projects to ensure good relations between all these aspects? There are resources in science studies, and other fields that specialise in social and technical relations, to support such a design process for energy infrastructures (Gabrys 2014; Watts 2014; Watts et al. 2018).

Experts and engineers can often miss the needs of people and publics. Device design is often a technical and proprietary process, but we might open these design processes to allow input and ideas from local experts, repositioning local communities as experts in their own seascape and its relations. Developers often seek to manage expectations of existing sea users and local communities, so they might inquire more broadly as to whether the community is open to MRE projects, and what expertise is available to them. Unlike wind energy, MRE design and implementation can be contingent on the complex sea environment, with many unknowns and scientific uncertainties. Local mariners (fishers, aquaculture workers, divers) are often the keepers of this local knowledge. Design processes could integrate this knowledge early on, helping to de-risk the outcome. Inquiries into local expertise and reception could highlight whether consent is likely or if there will be substantial resistance due to local mythologies and imaginaries.

MRE developers could learn from well-established approaches such as participatory design, co-design, and speculative design, which democratise design by emphasising the importance of location and participation of users and communities (Ehn et al. 2014; Kimura and Kinchy 2016).

The current statutory consultation process has rigid and specific legal frameworks, which can result in short bursts of intense community engagement and 'tick-box consultation'. However, device developers, conscious of the importance of their long-term relationship with a local community, would prefer a more expansive consultation. This would 
potentially de-risk projects. As one participant put it at our workshop, developers should "arrive early, and stay late" in a local community.

A related issue is how consultation is often conducted by a wide variety of third parties (often diverse consultancies, working on behalf of many different organisations). While this adequately fulfills legal requirements, it can fail to provide valuable feedback. A single, local point of contact between MRE developers and communities, such as a liaison person or a local 'champion' embedded in the community, could help bridge this gap.

Connecting back to MRE mythologies, a participatory design process could encompass social and cultural heritage and histories. This would affect how a new device forms a relationship to a local community and becomes accepted or not. For example, a MRE device could connect to existing cultural heritage of the sea, prior histories of energy extraction on land, sea ownership and rights disputes, or even public stories about the organisations, investors, or developers in circulation around the world. Reimagining the design process would allow for positive engagement in difficult socio-cultural issues. $\mathrm{SSH}$, from design and policy engagement to cultural research and arts projects, could become the vanguard for engaging with, and making visible, the existing cultural context for sea energy.

\subsection{Ecology of Approaches}

"Decisions are ultimately qualitative ... Putting numbers on something is usually a justification for what is a socially-driven decision"-guest expert on the limits of quantitative decision-making.

Rather than relying on a narrow set of methods, we propose an 'ecology of approaches' with diverse forms of evidence to understand the social impacts and relations in MRE. We should bring together quantitative analysis and qualitative methods, such as participatory mapping, ethnography, and cultural histories, to speak across industry, policy, and communities.

Different forms of narration, evidence, and language are used by different stakeholders for communications and knowledge transfer. SSH researchers have an important role to play in translating between these languages, bringing greater clarity to the views of stakeholders and conveying respect for their multiple knowledge systems. We propose going beyond merely quantifying environmental impacts towards understanding and translating the rich social and environmental interactions with MRE technologies (Harvey et al. 2016). 
MRE is a start-up industry, with financial investment often coming from venture capital. This carries the risks of hype and disappointment, as well as miscommunication. The sociological literature on expectation and anticipation demonstrates that these stories and predictions about future industry are performative (Brown and Michael 2003). Narratives told by industry to local communities, investors, and policymakers are crucial in changing the future of the industry. However, these three domains need different stories and evidence, since they have diverse concerns and objectives. SSH has a role to play here. SSH researchers have established methods for supporting collaboration between local communities and new industries, for example, semi-structured interviews, observational surveys, and ethnography. Secondly, SSH can document the diverse and rich maritime relations and history that all participants have, using a range of both qualitative and quantitative evidence. As deployment is always specific to a place, this evidence can be used to improve our understanding of how the industry can become sensitive to local histories, as well as how local communities can be sensitised to future industry. SSH also provides access to a global range of socio-cultural approaches taken to MRE to reduce perceived risk (Wright et al. 2018).

SSH, particularly Arts and Humanities, has approaches that can create sea and energy stories within a local community that can establish an overt relationship with MRE ('prime the area'), enabling a local community to be ready to engage with marine energy deployment. For two examples, see participatory story-mapping (Brennan 2018), a method which could be used to improve developers' knowledge of local resources, and an energy walk used to develop local public engagement with sea energy (Winthereik et al. in press).

Overall, the variety of different relationships with the sea and energy necessitate the use of equally varied approaches to research. We need to create bespoke methods with different options and timeframes, aiming to move beyond an 'us versus them' mindset, to an MRE 'development community' that includes developers, researchers, policymakers, and the local community.

\subsection{Conclusion}

"Show you've learnt, and hang around late in conversation so you can show that you've learnt"-guest expert on previous effective community engagement. 
The ecology of approaches to 'ownership' and the 'mythologies' created by communities around MRE should not be thought of as selfcontained events in time. Each failed or successful project leaves a legacy that contributes to future discourses. As MRE technologies, particularly tidal, are bound to a handful of specific locations, these legacies are of great importance. The development of an effective institutional memory can help avoid issues resulting from over-information and underpreparation of the actors involved (Alavi and Leidner 2001). This 'memory' is more than a simple collection of papers on previous applications, which are already somewhat available. Along with a strengthening of the record-keeping process, we propose that such a collective memory could be generated and maintained through an institution devoted to preserving and circulating information regarding the experiences of MRE developers (Corbett et al. 2017).

The future has an important role for marine energy, especially in a context of Blue Growth. As one of the workshop stakeholders said, commenting on the need to sensitise people with evidence-based information: "We have time to do this as this industry is not ready now". Communities in energy-rich waters have been exposed to partial information as developers have attempted to establish their presence in recent years. These experiences may generate positive and negative expectations of future development based on partial information flows generated outside of the public sphere.

Within a context of Blue Growth Strategy, anticipating and sustaining a dialogue with the relevant communities will create the social capital necessary to justly support the diffusion of marine energy. But how do we connect the past with this future?

Mythologies created by communities are one important catalyst. The interconnected work of geographers, sociologists, economists, and anthropologists has demonstrated how social interactions, mediated by institutions, can support the diffusion and development of new innovations (Brown 1981), including renewable energy technologies (Firestone et al. 2009; Graziano and Gillingham 2015). SSH can help developers and scientific institutions to develop that 'reflexive discourse' (Wynne 1992; Wynne 2006) necessary for creating long-lasting trust between all parties involved during the emergence of MREs. As mythologies change, and as memories of successful and failed projects accumulate, social scientists can fill the void between appearing and disappearing stakeholders.

One 'tool' for filling such a void could be found in the concept of 'bridger organisations' (Wilson and MacDonald 2018). These communicate across 
organisational, sectoral, and national boundaries to preserve memories, and transmit knowledge over extended time. The form of bridgers can vary depending on the underlying policy landscape, from non-governmental organisation to research institutions to independent state-run agencies.

A bridging institution of this kind for marine energy will play two roles. First, it can collect and synthesise the forms and materials of past development processes. Alone, this role is insufficient to guarantee that knowledge is passed on. Therefore, secondly, this institution can participate in sustained advocacy and engagement with the local communities, preparing and keeping them informed, and collecting and managing their changing expectations, concerns, and requests. Further, this institution could assist developers in their relationship-building process, lowering the risks associated with developing concepts of ownership, recording mythologies, and formulating a seascape where the spatial and temporal disparities can be understood by all stakeholders, thus operationalising the knowledge it has preserved.

On the basis of this, we have outlined some key opportunities for SSH in supporting MRE (Box 3.1).

\section{Box 3.1 Key opportunities for SSH-supported Marine Renewable Energy (MRE)}

- Create a bridger organisation for MRE to support enduring international knowledge.

- Understand different notions of ownership that underpin potential marine resource conflicts.

- Facilitate respectful collaborations across different knowledge systems and forms of evidence, and develop the institutions and processes that could bring all actors together to create shared visions for the local deployment of these nascent technologies.

- Develop and apply contextual information to MRE development, rather than extrapolating the findings from one technology or location to another.

- Take inclusive and creative approaches to design, accounting for different interests, knowledge systems, and geographies. Such design processes could help in developing a constructive, ongoing narrative of shared values and benefits and the co- $^{-}$ ownership of sociotechnical innovations. 
Overall, technocratic strategies for the terrestrial deployment of renewable energy have often met with significant opposition and delay due to a lack of meaningful engagement with different community and stakeholder groups. SSH and socio-cultural approaches can inform and intercede in Blue Growth, to limit the risk of similar problems occurring in marine energy development and to make both sustainable communities and sustainable energy.

\section{REFERENCES}

Alavi, M., \& Leidner, D. (2001). Review: Knowledge Management and Knowledge Management Systems: Conceptual Foundations and Research Issues. MIS Quarterly, 25(1), 107-136.

Anderson, B. (1999). Imagined Communities (2nd ed.). London: Verso.

Batibasqa, K., Overton, J., \& Horsley, P. (1999). Vanu: Land People and Culture of Fiji. In J. Overton \& R. Scheyvens (Eds.), Strategies for Sustainable Development Experiences from the Pacific. London: Zed Book.

Brennan, R. (2018). Re-storying Marine Conservation: Integrating Art and Science to Explore and Articulate Ideas, Visions and Expressions of Marine Space. Ocean \& Coastal Management. https://doi.org/10.1016/j.ocecoaman. 2018.01.036

Brown, L. (1981). Innovation Diffusion. New York: Methuen.

Brown, N., \& Michael, M. (2003). A Sociology of Expectations: Retrospecting Prospects and Prospecting Retrospects. Technology Analysis \& Strategic Management, 15(1), 3-18.

Corbett, J., Grube, D. C., Lovell, H., \& Scott, R. (2017). Singular Memory or Institutional Memories? Toward a Dynamic Approach. Governance, in press. https://doi.org/10.1111/gove.12340.

De Groot, J., Campbell, M., Reilly, K., Colton, J., \& Conway, F. (2018). A Sea of Troubles? Evaluating User Conflicts in the Development of Ocean Energy. In G. Wright, S. Kerr, \& K. Johnson (Eds.), Ocean Energy Governance Challenges for Wave and Tidal Stream Technologies (pp. 170-190). London: Earthscan.

Devine-Wright, P. (2009). Rethinking NIMBYism: The Role of Attachment and Place Identity in Explaining Place-protective Action. Journal of Community and Applied Psychology, 19, 426-441.

Ehn, P., Nilsson, E., \& Topgaard, R. (2014). Making Futures: Marginal Notes on Innovation, Design, and Democracy. Cambridge, MA: MIT Press.

Firestone, J., Kempton, W., \& Krueger, A. (2009). Public Acceptance of Offshore Wind Power Projects in the USA. Wind Energy, 12(2), 183-202.

Gabrys, J. (2014). A Cosmopolitics of Energy: Diverging Materialities and Hesitating Practices. Environment and Planning A, 46(9), 2095-2109. 
Graziano, M., \& Gillingham, K. (2015). Spatial Patterns of Solar Photovoltaic System Adoption: The Influence of Neighbors and the Built Environment. Journal of Economic Geography, 15, 815-839.

Graziano, M., Musso, M., \& Lecca, P. (2017). Historic Paths and Future Expectations: The Macroeconomic Impacts of the Offshore Wind Technologies in the UK. Energy Policy, 108, 715-730.

Haggett, C. (2008). Over the Sea and Far Away? A Consideration of the Planning, Politics and Public Perception of Offshore Wind Farms. Journal of Environmental Policy and Planning, 10(3), 289-306.

Harvey, P., Bruun Jensen, C., \& Morita, A. (Eds.). (2016). Infrastructures and Social Complexity: A Companion. New York: Routledge.

Jay, S. (2010). Built at Sea. Town Planning Review, 81(2), 173-191.

Johnson, K., Kerr, S., \& Side, J. (2013). Marine Renewables and Coastal Communities-Experiences from the Offshore Oil Industry in the 1970s and Their Relevance to Marine Renewables in the 2010s. Marine Policy, 38, 491-499.

Jones, P., Qiu, W., \& De Santo, E. (2013). Governing Marine Protected Areas: Social-ecological Resilience Through Institutional Diversity. Marine Policy, 41, $5-13$.

Kerr, S., Colton, J., Johnson, K., \& Wright, G. (2015). Rights and Ownership in Sea Country: Implications of Marine Renewable Energy for Indigenous and Local Communities. Marine Policy, 52, 108-115.

Kerr, S., Johnson, K., \& Weir, S. (2017). Understanding Community Benefit Payments from Renewable Energy Development. Energy Policy, 105, 202-211.

Kimura, A. H., \& Kinchy, A. (2016). Citizen Science: Probing the Virtues and Contexts of Participatory Research. Engaging Science, Technology, and Society, 2(0), 331-361.

Ladenburg, J. (2008). Attitudes Towards on-land and Offshore Wind Power Development in Denmark; Choice of Development Strategy. Renewable Energy, 33(1), 111-118.

Levy, D., \& Spicer, A. (2013). Contested Imaginaries and the Cultural Political Economy of Climate Change. Organization, 20(5), 659-678.

Midgley, M. (2004). The Myths We Live By. London: Routledge.

Ocean Energy Europe (OEE). (2016). Ocean Energy Strategic Roadmap: Building Ocean Energy for Europe. Brussels: European Commission.

Rennie, F., \& Billing, S. (2015). Changing Community Perceptions of Sustainable Rural Development in Scotland. Journal of Rural Community Development, $10(2), 35-46$.

Smith, H. D., Ballinger, R. C., \& Stojanovic, T. A. (2012). The Spatial Development Basis of Marine Spatial Planning in the United Kingdom. Journal of Environmental Policy and Planning, 14, 29-47. 
Watts, L. (2014). Liminal Futures: A Poem for Islands at the Edge. In J. Leach \& L. Wilson (Eds.), Subversion, Conversion, Development: Cross-Cultural Knowledge Exchange and the Politics of Design. Cambridge MA: MIT Press.

Watts, L., \& Winthereik, B. R. (2018). Ocean Energy at the Edge. In G. Wright, S. Kerr, \& K. Johnson (Eds.), Ocean Energy: Governance Challenges for Wave and Tidal Stream Technologies. Abingdon and New York: Routledge.

Watts, L., Auger, J., \& Hanna, J. (2018). The Newton Machine: Reconstrained Design for Energy Infrastructure. In P. Sumpf \& C. Büscher (Eds.), Control, Change and Capacity-Building in Energy Systems: SHAPE ENERGY Research Design Challenge (pp. 135-142). Cambridge: SHAPE ENERGY.

Wilson, L., \& MacDonald, B. H. (2018). Characterizing Bridger Organizations and Their Roles in a Coastal Resource Management Network'. Ocean and Coastal Management, 153, 59-69.

Winthereik, B. R., Maguire, J., \& Watts, L. (in press). The Energy Walk: Infrastructuring the Imagination. In J. Vertesi \& D. Ribes (Eds.), Handbook of Digital STS. Princeton, NJ: Princeton University Press.

Wright, G., O’Hagan, A.M., de Groot, J., Leroy, Y., Soininen, N., Salcido, R., Castelos, M., Jude, S., Rochette, J., \& Kerr, S. (2016). Establishing a Legal Research Agenda for Ocean Energy. Marine Policy, 63, 126-134.

Wright, G., Kerr, S., \& Johnson, K. (Eds.). (2018). Ocean Energy: Governance Challenges for Wave and Tidal Stream Technologies. Abingdon and New York: Routledge.

Wynne, B. (1992). Misunderstood Misunderstanding: Social Identities and Public Uptake of Science. Public Understanding of Science, 1(3), 281-304.

Wynne, B. (2006). Public Engagement as a Means of Restoring Public Trust in Science-Hitting the Notes, But Missing the Music? Public Health Genomics, $9(3), 211-220$.

Open Access This chapter is licensed under the terms of the Creative Commons Attribution 4.0 International License (http://creativecommons.org/licenses/ by $/ 4.0 /$ ), which permits use, sharing, adaptation, distribution and reproduction in any medium or format, as long as you give appropriate credit to the original author(s) and the source, provide a link to the Creative Commons license and indicate if changes were made.

The images or other third party material in this chapter are included in the chapter's Creative Commons license, unless indicated otherwise in a credit line to the material. If material is not included in the chapter's Creative Commons license and your intended use is not permitted by statutory regulation or exceeds the permitted use, you will need to obtain permission directly from the copyright holder.

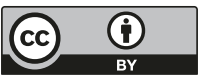

